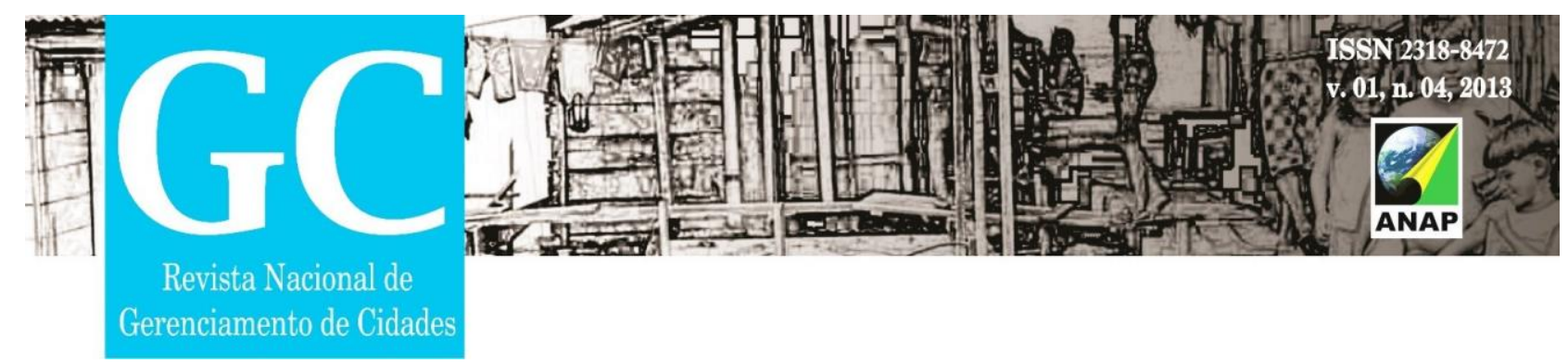

Titulo do Trabalho

\title{
PLANEJAMENTO URBANO EM CONJUNTOS HABITACIONAIS
}

Nome do Autor (a) Principal

Jeferson Luís Martins de Freitas

Nome (s) do Coautor (a) (s)

Jessé Martins de Freitas

Nome (s) do Orientador (a) (s)

Jeane Aparecida Rombi de Godoy Rosin

Instituição ou Empresa

\section{FACCAT- Faculdades de Ciências Contábeis e Administração de Tupã}

Instituição (s) de Fomento

\section{Nome da Instituição}

E-mail de contato

jessefrts@gmail.com

Palavras-chave

Conjuntos habitacionais, planejamento urbano, periferias urbanas.

\section{INTRODUÇÃO}

A partir de diagnósticos extraídos, esta breve reflexão pretende estudar e analisar os principais problemas que afetam os Conjuntos Habitacionais - Jamil Dualibi e Papa João Paulo II, empreendimentos habitacionais de interesse social, localizados na cidade de 


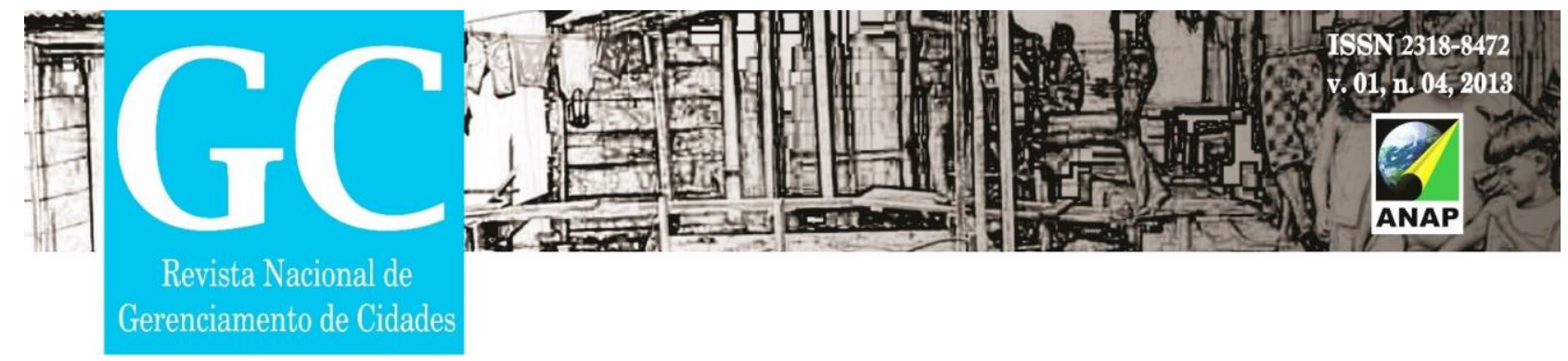

Tupã- SP, especificamente às questões cruciais que abalam a vida de seus moradores. Principalmente para o tema proposto, o Planejamento Urbano deve ser uma ferramenta estratégica dedicada a organização de uma cidade, além de se configurar como um instrumento essencial apto em responder as diversas demandas sempre crescentes no contexto urbano. A partir dos princípios e mecanismos elencados no Estatuto das Cidades, o plano diretor é certamente a principal ferramenta para uma gestão urbana que se deseja sustentável, justa e humana. Entretanto a realidade de um porcentual elevado, que a cada ano cresce assustadoramente, ao apresentar indicadores que mostram a ineficácia dos sistemas de gestão urbana, adotados em muitas localidades desse país. Quando a questão analisada, envolve os empreendimentos habitacionais de interesse social, a situação se agrava em proporções gigantescas, as quais podem em muitos casos ser atribuídas a uma formatação equivocada da própria Política Habitacional, que ao ser elaborada desconsiderou a grande diversidade relacionada aos aspectos físicos, sociais, econômicos e culturais das cidades no Brasil, ao impor um modelo único para todas as localidades beneficiadas.

Não se pode deixar de considerar que a questão habitacional é fundamental para o atendimento das demandas alarmantes, principalmente quanto se tem como referencia o alto déficit habitacional registrado pelos órgãos governamentais, além dos cenários apresentados na paisagem das cidades, onde a questão é irrefutável.

Frente ao exposto, é mais do que necessário, a proposição de um novo modelo de Política Habitacional a ser novamente revisado e editado pelo Estado. As atuais formatações que orientam a implementação de políticas públicas dedicadas a problemática habitacional, não tem alcançado resultados satisfatórios(ROSIN,2011), ao desconsiderarem a grande diversidade da dinâmica da vida urbana. Dessa forma, torna-se fundamental a revisão dos princípios que orientam a formatação de tais políticas, como essencialmente a elaboração dos projetos urbanos, os quais deveriam observar os princípios de sustentabilidade, visando uma integração de adequadas tecnologias, valores e conhecimentos que proporcionassem qualidade não apenas da unidade habitacional, mas também do empreendimento urbanístico. Num entendimento genérico o 


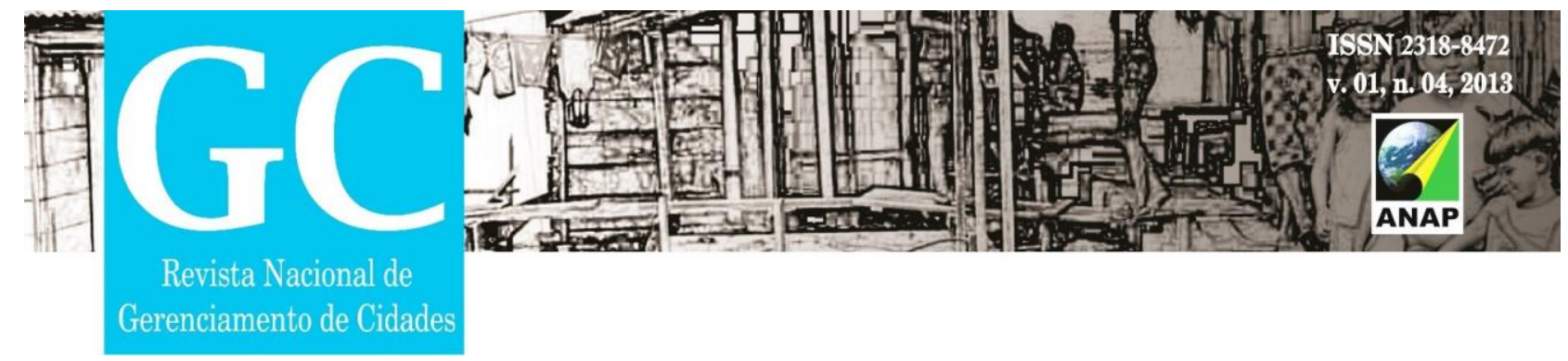

planejamento, pode ser considerado uma forma de atividade - ação contínua e permanente, a fim de buscar alternativas aos diversos problemas e demandas que afetam a vida em sociedade, como as várias situações econômicas, sociais, culturais peculiares do viver em cidades na tentativa de suprir as necessidades e expectativas da população.

A falta de planejamento, em muitas cidades brasileiras é a razão de problemas muitas vezes de grande complexidade, onde os mesmos estão relacionados as questões ambientais e acabam por atingir vários setores, dentre eles os habitacionais. Neste sentido, a preocupação com assuntos vinculados a questão ambiental poderia colaborar para uma gestão integrada no cuidado com a vida urbana em suas diversas esferas.

Desse modo o presente trabalho, procura oferecer uma contribuição ao estudo projeto urbano - habitacional, voltado principalmente ao planejamento urbano em uma área específica localizada na cidade de Tupã, tomando por base e objeto de estudo os Conjuntos Habitacionais Jamil Dualibi e Papa João Paulo II.

\section{OBJETIVO GERAL}

- Estudar o processo de planejamento adotado na implantação de conjuntos habitacionais de interesse social, voltados para a população de baixa renda, localizados na cidade de Tupã, buscando identificar os pontos de conflito e os impactos produzidos.

\section{OBJETIVOS ESPECÍFICOS}

- Analisar o desenvolvimento do bairro, sua integração com o tecido urbano.

- Identificar as demandas decorrentes de falhas técnicas de implantação do empreendimento, a partir do depoimento de seus moradores. 


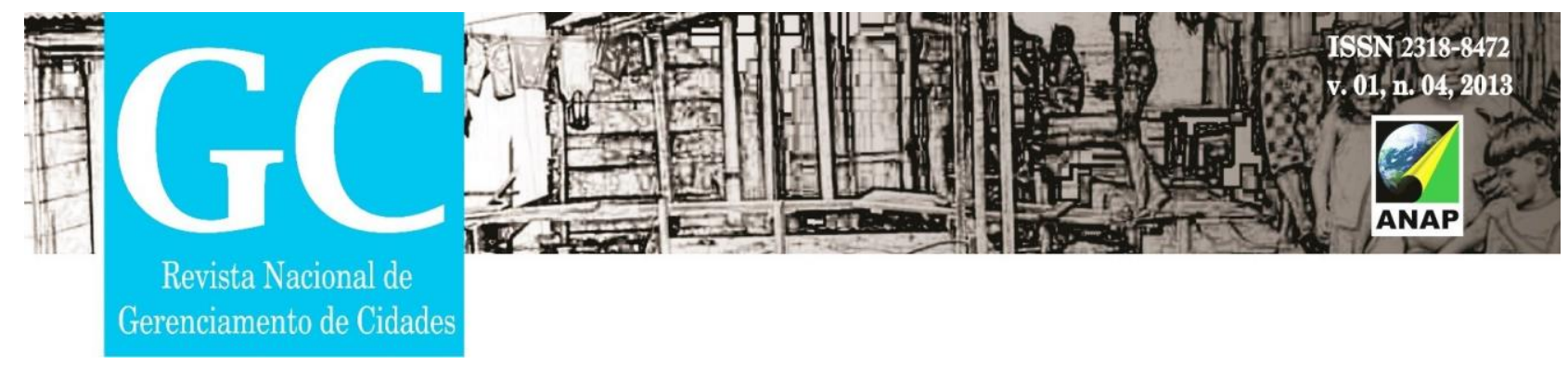

\section{METODOLOGIA}

Para a realização dessa pesquisa ocorreu, inicialmente, uma pesquisa bibliográfica cientifica, com vistas a buscar uma melhor compreensão da emergência de implantação do bairro, seu desenvolvimento e os problemas nele existentes.

A pesquisa bibliográfica também nos permitiu a compreensão de questões ideológicas que envolvem o processo de formação de bairros populares no município de Tupã, o que também incluiu uma leitura de textos relacionados ao Planejamento Urbano para cidades de pequeno e médio porte.

Os procedimentos metodológicos ainda incluíram a aplicação de questionários de base quantitativa e qualitativa junto à população residente, com vista a identificar o perfil sócio econômico, bem como o conhecimento das demandas e expectativas desses indivíduos, no tocante a sua percepção crítica dos principais problemas existentes no bairro, possíveis soluções e a postura do poder publico no atendimento a seus reais interesses e necessidade.

\section{RESULTADO (S)}

O estudo da implantação dos empreendimentos habitacionais, visando a constituição de bairros, localizados na periferia, em qualquer cidade, não deve estar dissociado de um Planejamento Urbano adequado. Esse por sua vez, reflete, também, a postura política dos gestores municipais no que diz respeito aos interesses da política pública de desenvolvimento urbano, os quais deveriam priorizar em seus planos de governo, ações aptas em proporcionar às melhores condições e qualidade de vida de seus habitantes.

Por outro lado, o diagnóstico desses espaços, a partir da pesquisa de campo nos permitiu compreender a visão de seus moradores sobre essas políticas e seus efeitos, o 


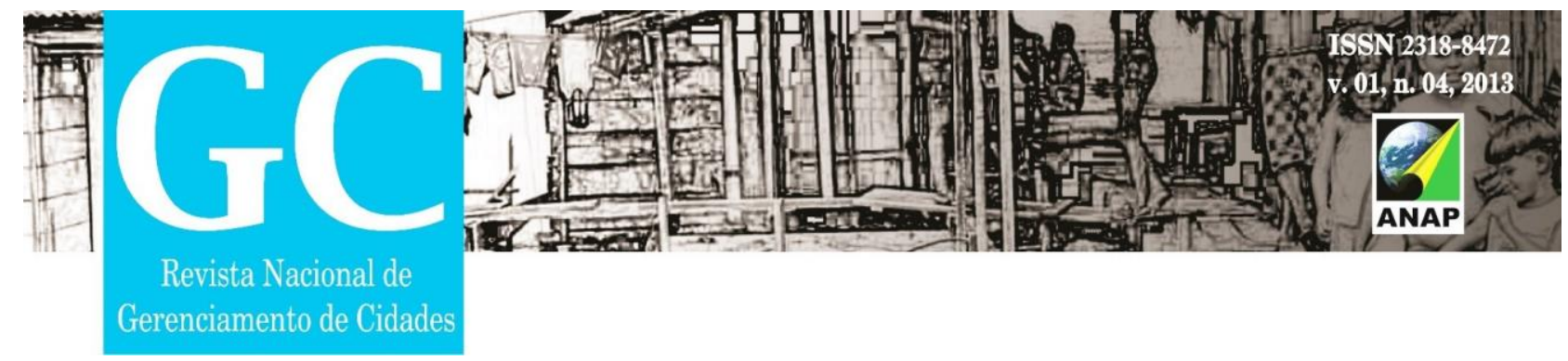

que nos possibilitou, a partir dos resultados obtidos, a elaboração de sugestões para novos processos de Planejamento Urbano, onde seja possível projetos urbanísticos pautados pelos princípios sustentáveis, de cidadania, que possam permitir a inclusão socioespacial, a fim de contribuir para sua real autonomia, e por consequência, melhorar a qualidade de vida de seus moradores e amenizar os impactos que afetam as condições essenciais de uma vivência digna em cidades.

\section{CONSIDERAÇÕES FINAIS}

Podemos afirmar que a partir de uma análise histórica de formação e desenvolvimento dos bairros Jamil Dualibi e Papa João Paulo II, o trabalho de campo realizado, nos permitiu perceber que, nos dias atuais, com 4 anos desde sua formação, o bairro apresenta uma significativa melhoria na qualidade de vida de seus moradores.

No entanto consideramos que apesar disso, pode-se constatar ainda um déficit em vários de seus aspectos, cujo registro adveio, em parte, dos apontamentos da própria população que reside no local. A partir destas considerações, os conjuntos habitacionais se mostram segregadores, uma vez que esses não oferecem infraestruturas favoráveis aos moradores e dificultam o acesso desses ao seu local de trabalho na cidade, dentre outros problemas.

Tal constatação nos possibilitou a identificação de pontos críticos a serem analisados e estudados cuidadosamente, servindo de base e contribuição para um planejamento urbano mais eficaz e politicamente comprometido com os bairros periféricos da cidade.

\section{REFERÊNCIAS}

MASCARÓ, Juan Luis; Loteamentos urbanos. Porto Alegre, 2003. 210 p. : il. 


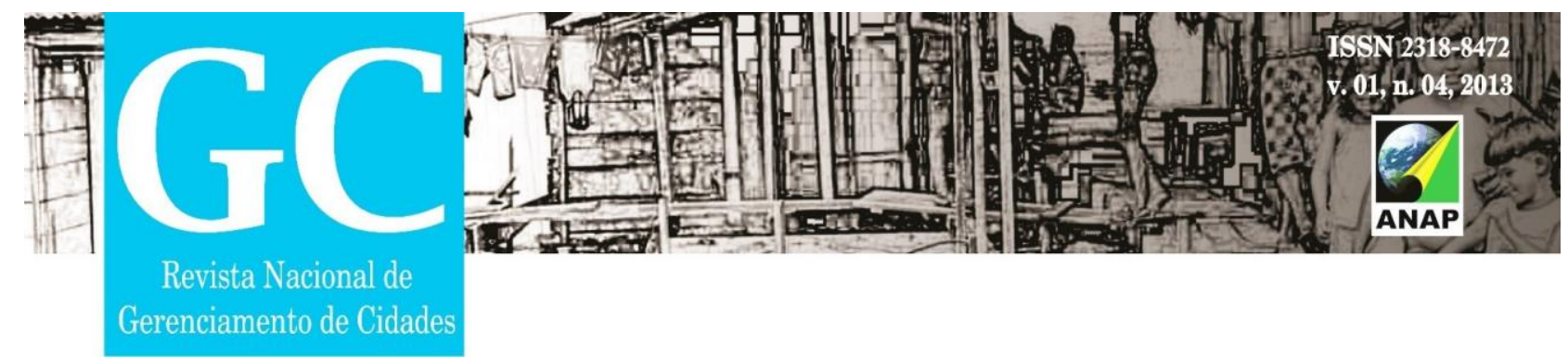

FERREIRA, João Sette Whitaker. Produzi casas ou construir cidades? Desafios para um novo Brasil urbano. Parâmetros de qualidade para a implementação de projetos habitacionais e urbanos. São Paulo: LABHAB; FUPAM, 2012. 200 p. :il.

COSTA, Carlos Magno Miqueri. Direito Urbanístico Comparado - Planejamento Urbano Das Constituições aos Tribunais Luso-Brasileiros. Editora Juruá. 2009. 